\title{
THE EFFECT OF SOME TECHNOLOGICAL PRODUCTION VARIABLES ON MECHANICAL AND PHYSICAL PROPERTIES OF PARTICLEBOARD MANUFACTURED FROM COTTON (Gossypium hirsutum) STALKS
}

\author{
Morteza Nazerian $^{1, \star}$, Zahra Beyki ${ }^{1}$, Rahiim Mohebbi Gargarii ${ }^{1}$, Farhad Kool $^{1}$
}

\begin{abstract}
The current study aims to improve properties of particleboard manufactured from cotton (Gossium hirsutum) stalks glued with urea formaldehyde. To this aim, panel density (at three levels: 0,$5 ; 0,65$ and $0,8 \mathrm{~g} / \mathrm{cm}^{3}$ ), press temperature (at two levels: 150 and $180^{\circ} \mathrm{C}$ ) and press closing speed (at two levels: 4 and $8 \mathrm{~mm} / \mathrm{s}$ ) were selected as independent variables. The mechanical properties consist of modulus of rupture, modulus of elasticity and internal bonding and physical behaviors such as water absorption and thickness swelling of panels were determined. Results showed that with increasing the density of panels and press temperature modulus of rupture, modulus of elasticity and internal bonding of panels increased, while bending strengths of panels were differently affected by press closing speed compared to the internal bonding, so that with increasing the press closing speed modulus of rupture increased, but internal bonding decreased. Moreover, increasing panel density and press temperature, water absorption and thickness swelling of panels decreased. The press closing speed affected the water absorption and thickness swelling, insignificantly.
\end{abstract}

Keywords: Cotton stalks, density, mechanical properties, particleboard, physical properties, press closing speed.

\section{INTRODUCTION}

In recent years, attention is paid to using lignocellulosic residues obtained from agricultural crops, especially in wood and paper industries. Many countries including Iran, face the difficulties of lack of wood raw material since most of its forested regions are not suitable for production. Hence, it is unavoidable to use agricultural wastes due to the lack of wood raw materials and the sharp decline of forest resources (Kord et al. 2015, Guler et al. 2006). All of these issues show the relative advantages and the importance of the extension of using these residues on areas of wood industries.

Nowadays, agricultural wastes are burned in most farms of many countries. Aside from the fact that burning agricultural wastes eliminates important lignocelluloses resources, it also results in severe erosion and decline of the soil's organic materials and its fertility, creation of carbon gases and damage to the environment. Many researches are conducted on the provision of composite materials based on using renewable lignocellulosic resources in the entire world. One of these agricultural wastes is cotton stalk. Cotton is an annual plant growing in temperate regions, with a height from 60 to $100 \mathrm{~cm}$. Cotton stalk's density is $0,41 \mathrm{gr} / \mathrm{cm}^{3}$ and it can be categorized as a very light wood in wood species, but the application of these wastes has its own disadvantages that can strongly affect the wood-based composite materials properties, including the high moisture absorption of the composite products due to the pits on the cotton stalk (Shokouhi 1997). In addition, 26\% of the cotton stalk consists of bark. Therefore, it can be predicted that many properties of different types of panels manufactured from cotton stalks are negatively affected (Kargarfard et al. 2006). 
Mechanical and physical properties of particleboard can be affected by many variables, such as panel density, wood species, shelling ratio, and press variables. JaniSaad and Kamal (2012) examined the effect of three different densities on a particleboard made of hemp and the results showed that increasing the density, its dimensional stabilities and mechanical properties improve. Kadja et al. (2011) conducted a research on making particleboard made of cotton stalk at the pressing temperature $140^{\circ} \mathrm{C}$. The results showed that the flexural strength (MOR and MOE) of a particleboard made of cotton stalk with bone glue is more than that made of bamboo (Okubo et al. 2004) and hemp (Kalaycioglue and Nemli 2006).

The results of the research by Kehr and Scheolzel (1967) showed that increasing the press temperature from 175 to $210^{\circ} \mathrm{C}$, the board's core temperature reaches $100^{\circ} \mathrm{C}$ sooner, therefore, stronger connections are produced in core layer, and physical and mechanical strengths improve. Warmbier et al. (2011), conducted a research to reveal the effect of the press closing time on the particleboard is mechanical properties and found that increasing the press closing speed, would improve the mechanical strength.

In the studies conducted so far, the effect of the board's density, the press temperature and the closing speed of the press opening, simultaneously, on the properties of the particleboard manufactured from lignocellulosic materials is underexplored. Hence, the purpose of the current research is to examine the use of cotton stalk as a raw material for producing particleboard according to the change in the construction variables mentioned.

\section{MATERIALS AND METHODS}

Cotton stalk (Gossypium hirsutum L.) was provided from the northern region of Iran (Golestan Province). The resin used was powder urea-formaldehyde produced by Samed Glue Producing Company, Mashhad. The technical properties of the resin were as follows: solid materials $63 \%$, viscosity $350 \mathrm{cp}$, gel time $60 \mathrm{~s}$, and density of $1,26 \mathrm{~g} / \mathrm{cm}^{3}$.

After being transferred to the laboratory, the cotton stalk was manually peeled, and was ground by disc mill (DM 200, produced by Retsch Co., Germany) into particles usable for making a particleboard with the approximate dimensions $20 \mathrm{~mm}$ (length), $5 \mathrm{~mm}$ (width) $\times 1 \mathrm{~mm}$ (thickness). The particles moisture was stabilized at $5 \%$ according to their moisture balance with the environment to produce a cake. After weighing the particles and resin in terms of the treatment number of any board, the particles were stored in plastic bags. Cotton particles were placed into the blender and a certain amount of water (according to the cake's final moisture, i.e. $12 \%$ ) was sprayed on them. After mixing completely and when the moisture was distributed on the particles (for $5 \mathrm{~min}$ ), uniformly, the glue powder was sprinkled onto the particles in three stages for more proper distribution of resin and they were mixed for 6 minutes. The resin constituted $10 \%$ of the final total weight of the board. After mixing the particles and resin, a wooden mold with the dimensions of $30 \times 30 \mathrm{~cm}$ was used to form a cotton particle cake, and the glued particles were manually sprinkled as uniform layers inside the mold. After the cake was formed and was removed from the mold, it was transferred inside the press. After pressing, the prepared boards were kept for 10 days in laboratory for conditioning and creating uniform moisture in the board and also for balancing the internal stress. In this research, two temperatures 150 and $180^{\circ} \mathrm{C}$, two press closing speed 4 and $8 \mathrm{~mm} / \mathrm{s}$ and three different densities 0,$5 ; 0,65$ and $0,8 \mathrm{~g} / \mathrm{cm}^{3}$ of panels were used as variables for manufacturing of the boards. The press time was 8 minutes and the press pressure was also $30 \mathrm{~kg} / \mathrm{cm}^{2}$.

The technique by Neusser and Karmes (1967) was used to determine the density profile based on the specimens' thin pilling, to evaluate the effect of the change in independent variables on the changes in thickness profile density and changes in the boards' physical and mechanical behavior. 
A total of 126 specimens including 3 panels from each test specimen, and 6 specimens from every panel type were prepared according to the EN 326-1, to determine the boards' physical and mechanical properties. The bending strength (MOR) and modulus of elasticity (MOE) were determined based on EN 310 Standard, the internal bonding strength (IB) was determined based on EN 319 Standard. Loading speed was $5 \mathrm{~mm} / \mathrm{min}$ so that failure would occur within an average of $60 \pm 30 \mathrm{~s}$. In order to estimate dimensional changes and content of water absorption, the specimens' thickness swelling $\left(\mathrm{TS}_{24 \mathrm{~h}}\right)$ was determined based on EN 317 Standard, and resistance to water absorption $\left(\mathrm{WA}_{24 \mathrm{~h}}\right)$ was also determined. The obtained results were analyzed as multifactorial analyses test using Duncan's Multiple Range Test (DMRT). Using this statistical method, the direct and bilateral effects of any variables on the properties being studied were analyzed at the level of confidence $95 \%$.

\section{RESULTS AND DISCUSSION}

All variables including the board's density, the pressing temperature and the press closing speed significantly affected MOR and MOE of the specimens at the level of confidence $99 \%$, in a way that through increasing the density from 0,5 to $0,8 \mathrm{~g} / \mathrm{cm}^{3}$, the MOR and MOE increased, too (Table 1 and Figure 1).

Table 1. Analysis of variance of mechanical and physical data.

\begin{tabular}{|c|c|c|c|c|c|c|}
\hline Variation sources & df & MOR & MOE & IB & WA & TS \\
\hline Model & 11 & $133,706^{* *}$ & $348,671^{* *}$ & $237,7^{* *}$ & $168,354^{* *}$ & $70,717^{* *}$ \\
\hline Density & 2 & $659,6^{* *}$ & $1810^{* *}$ & $1020^{* *}$ & $888,19^{* *}$ & $334,9^{* *}$ \\
\hline Press temperature & 1 & $58,089^{* *}$ & $95,83^{* *}$ & $272,54^{* *}$ & $39,8^{* *}$ & $73,8^{* *}$ \\
\hline Press closing time & 1 & $69,4^{* *}$ & $40,1^{* *}$ & $95^{* *}$ & $3,5^{\mathrm{n} . \mathrm{s}}$ & $0,869^{\text {n.s }}$ \\
\hline $\begin{array}{l}\text { Density*press } \\
\text { temperature }\end{array}$ & 2 & $2,68^{\text {n.s }}$ & $26,25^{* *}$ & $88,65^{* *}$ & $9,2^{* *}$ & $4,98^{* *}$ \\
\hline $\begin{array}{l}\text { density * press closing } \\
\text { speed }\end{array}$ & 2 & $4,56^{*}$ & $5,499^{* *}$ & $9,75^{* *}$ & $5,49^{* *}$ & $8,84^{* *}$ \\
\hline $\begin{array}{l}\text { Press } \\
\text { temperature*press } \\
\text { closing speed }\end{array}$ & 1 & $2,12^{\mathrm{n} . \mathrm{s}}$ & $6,1^{\text {n.s }}$ & $0,714^{\text {n.s }}$ & $0,016^{\text {n.s }}$ & $0,327^{\mathrm{n} . \mathrm{s}}$ \\
\hline $\begin{array}{l}\text { Density*press } \\
\text { temperature *press } \\
\text { closing speed }\end{array}$ & 2 & $3,714^{*}$ & $4,873^{* *}$ & $4,524^{* *}$ & $1,379^{\text {n.s }}$ & $2,667^{\text {n.s }}$ \\
\hline
\end{tabular}

Since the board's density is a factor affecting all of its physical and mechanical properties, by increasing the compaction and mass of the wood panel, the compression and contact between the particles increases and stronger connections are created between them. Increasing the board's density, the contact area between the particles increases and the performance of the connection area of the glue improves compared to the lower density in the particleboard (Hiziroglu et al. 2005). Particleboard's density is directly related to the cake's compression under the press, so that increasing the compression of the particles, the mechanical strength also increases. 


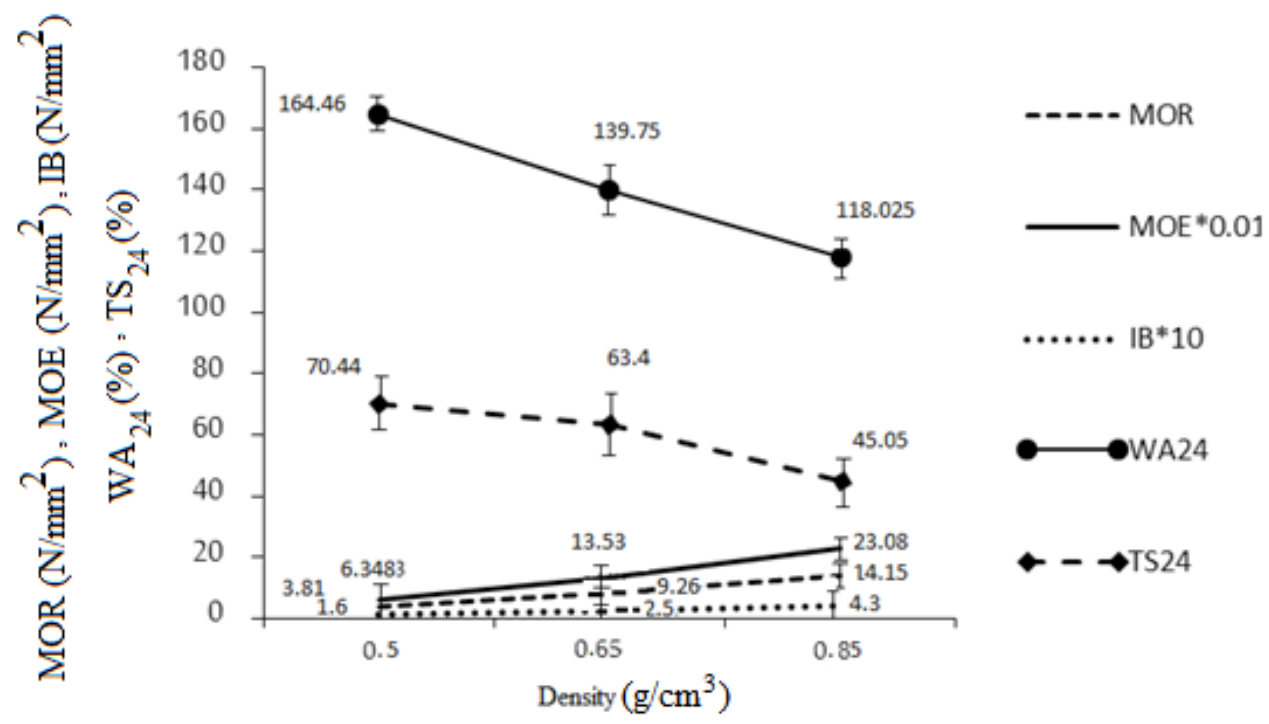

Figure 1. Direct effect of panel density on MOR, MOE, IB, $\mathrm{WA}_{24}$ and $\mathrm{TS}_{24}$.

Also increasing the temperature from 150 to $180^{\circ} \mathrm{C}$, the specimens' MOR and MOE increased (Figure 2). The main role of heat to increase the bending strength can be stated to make the particles soft and increase their compression. When heat increases, empty spaces decrease due to increasing in softening, compacting, and also speed of reaching to the permanent deformations of particles. So, the particles' overlapping coefficient increases and the bending strengths improve (Tabarsa and Chui 2000).

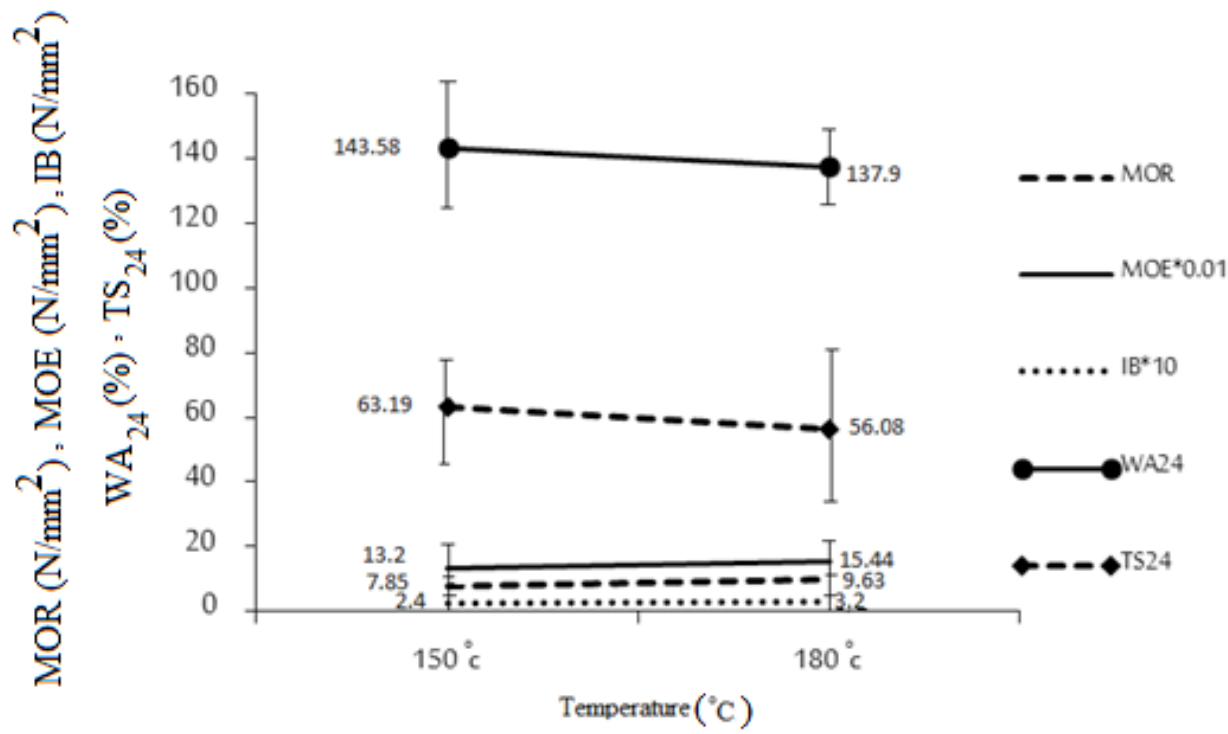

Figure 2. Dirrect effect of press tempreature on $\mathrm{MOR}, \mathrm{MOE}, \mathrm{IB}, \mathrm{WA}_{24}$ and $\mathrm{TS}_{24}$. 
By increasing the closing speed of the press opening from 4 to $8 \mathrm{~mm} / \mathrm{s}$, the specimens' MOR and MOE increased (Figure 3). Moreover, increasing press closing speed, stiffened surface layers of the boards. This makes the panel surface layers more compact, and increases MOR and MOE that are more dependent on the top and bottom surface layers' density of the board (Wu and Suchland 1997).

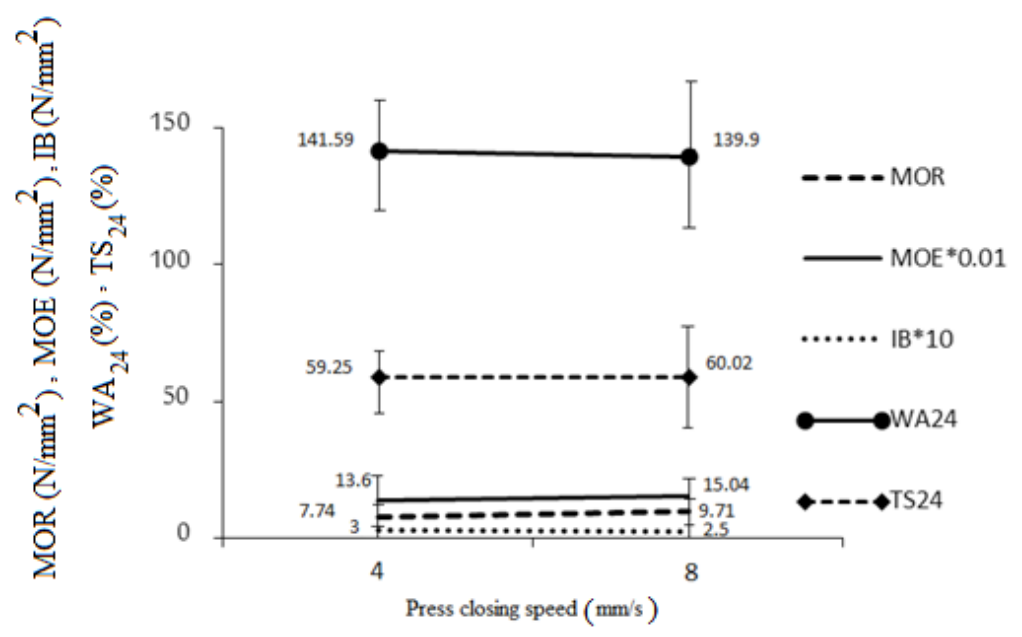

Figure 3. Direct effect of press closing speed on MOR, MOE, IB, $\mathrm{WA}_{24}$ and $\mathrm{TS}_{24}$.

The bilateral effects of the density and the press temperature and the bilateral effect of the density and the press closing speed on MOE are significantly different at the level of confidence $99 \%$. The specimens with the density of $0,8 \mathrm{~g} / \mathrm{cm}^{3}$ and the press temperature $180{ }^{\circ} \mathrm{C}$ (Figure $4 \mathrm{a}$ ) had the highest modulus of elasticity, and specimens with the density of $0,8 \mathrm{~g} / \mathrm{cm}^{3}$ and the press closing speed $8 \mathrm{~mm} / \mathrm{s}$ had the highest MOR and MOE (Figure $4 b$ and $c$ ).
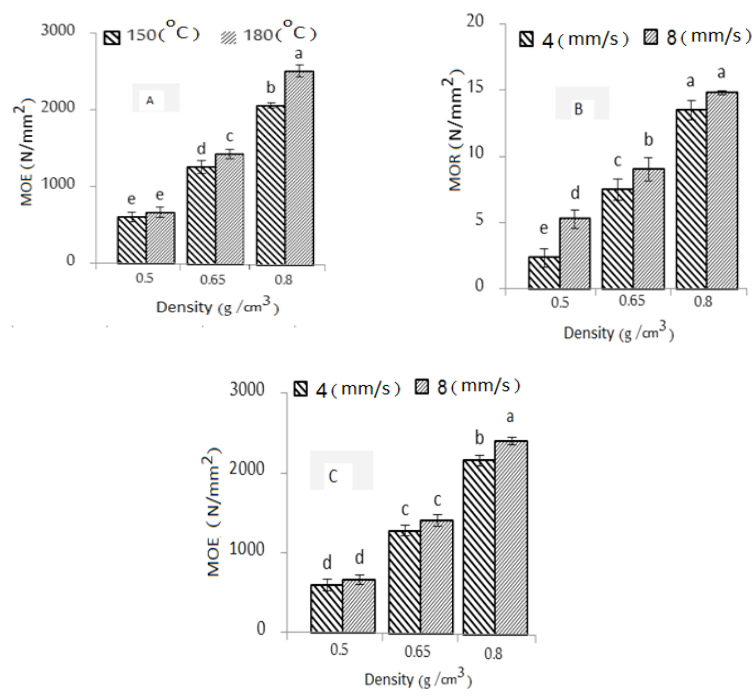

Figure 4. Bilateral effect of panel density and press temperature on MOE (A), panel density and press closing speed on MOR (B) and panel density and press closing speed on MOE (C); Note: While the different letters on the columns represent statistical differences at $95 \%$ confidence level, values having the same letter are not significantly different (Duncan's Multiple Range Test). 
The bilateral effects of the density and the closing speed of the press opening on MOR are significantly different at the level of confidence $95 \%$, and specimens with the density of $0,8 \mathrm{~g} / \mathrm{cm}^{3}$ and the press closing speed $8 \mathrm{~mm} / \mathrm{s}$ had the highest MOR. The mutual effect of the density, press temperature and closing speed on MOR and MOE is significantly different at the level of confidence $95 \%$, so that specimens with the density of $0,8 \mathrm{~g} / \mathrm{cm}^{3}$, press temperature $180^{\circ} \mathrm{C}$ and closing speed of the press opening $8 \mathrm{~mm} / \mathrm{s}$ had the highest MOR (Figure 5a) and MOE (Figure 5b). The bilateral effect of the density and press temperature on MOR and the bilateral effect of the press temperature and closing speed on MOR and MOE had no significant influence.
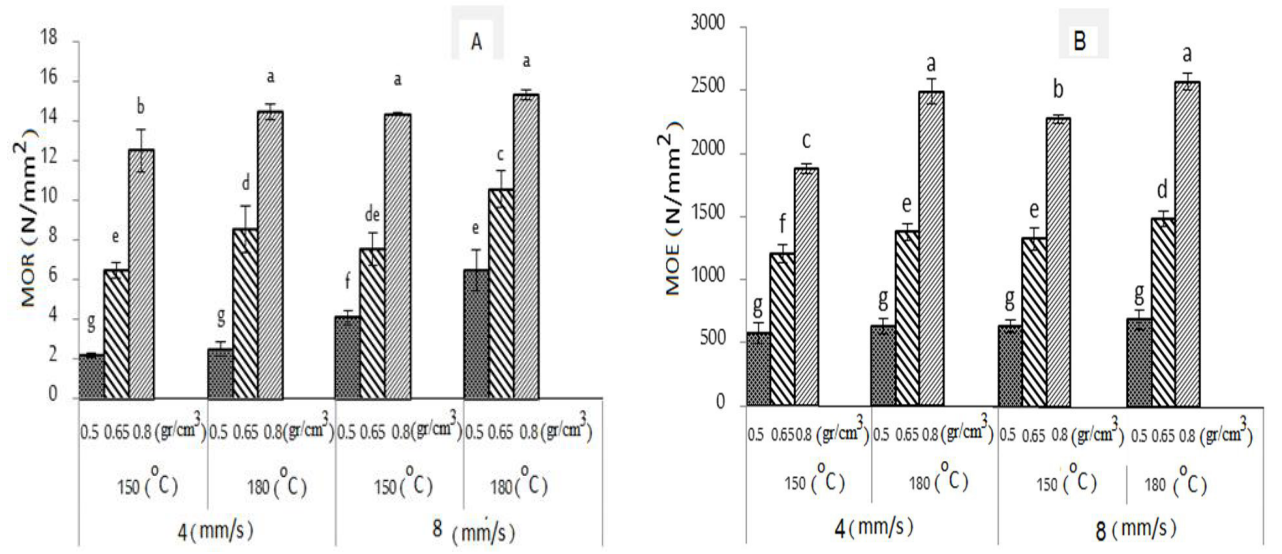

Figure 5. Mutual effect of panel density, press temperature and closing speed on MOR (A) and MOE (B); Note: While the different letters on the columns represent statistical differences at $95 \%$ confidence level, values having the same letter are not significantly different (Duncan's Multiple Range Test).

According to Figure 6, specimens prepared at the temperature $180^{\circ} \mathrm{C}$, with the press closing speed $8 \mathrm{~mm} / \mathrm{s}$ and the density of $0,8 \mathrm{~g} / \mathrm{cm}^{3}$ had the highest density at the surface layers. While, specimens prepared at the temperature $180^{\circ} \mathrm{C}$ with the press closing time $4 \mathrm{~mm} / \mathrm{s}$ had the lower density at surface layers and highest IB (Figure 8). It is through the press closing time that upper and lower surface layers of the board become brittle and hence, the surface layers become more compact, and MOR and MOE, which more than anything else depend on the surface layers' density, increase. Also, increasing the closing time of the press opening, more time is provided for core layer and the particles are interwoven more; and the core layer's density increases, while the average density is constant and hence, the IB increases. These results are consistent with those obtained by Wang et al. (2004).

The results show that the direct effect of the density, press temperature and the press closing speed on the boards' internal bonding (IB) is significantly different at the level of confidence $99 \%$, so that by increasing the boards' density, press temperature and decreasing the press closing speed, the IB increases (Figure 1, 2 and 3). Increasing the density, the empty space decreases and particles are more connected to each other; therefore, more heat transfers to the core layer of the board due to the increase in the pressing temperature, and particles are more soft and compact due to the increase in the heat transfer rate, and subsequently, the internal bonding increases (Candan and Akbulut 2015). For coarser particles used in surface layers that are mainly parallel to the press plates, the resin in the particles' cross section is not involved in the adhesion process, while some resin is absorbed and indeed, particles are separated and empty spaces will occur on the particles' sections (Tousi et al. 2015). Increasing the heat, empty spaces decrease, because particles become softer and more compact and reaches to permanent deformation. So, particles are more overlapped and the strengths improve, especially the internal bonding strength. In addition, with an increase in temperature, particles become softer and the resin is polymerized well in the core layer and thus, the particleboards' internal bonding increases (Sernek and Famke 2007). In fact, the high temperature makes the particles softer, stabilizes the cells 
at the stable compression position, and increases the internal bonding of panels.

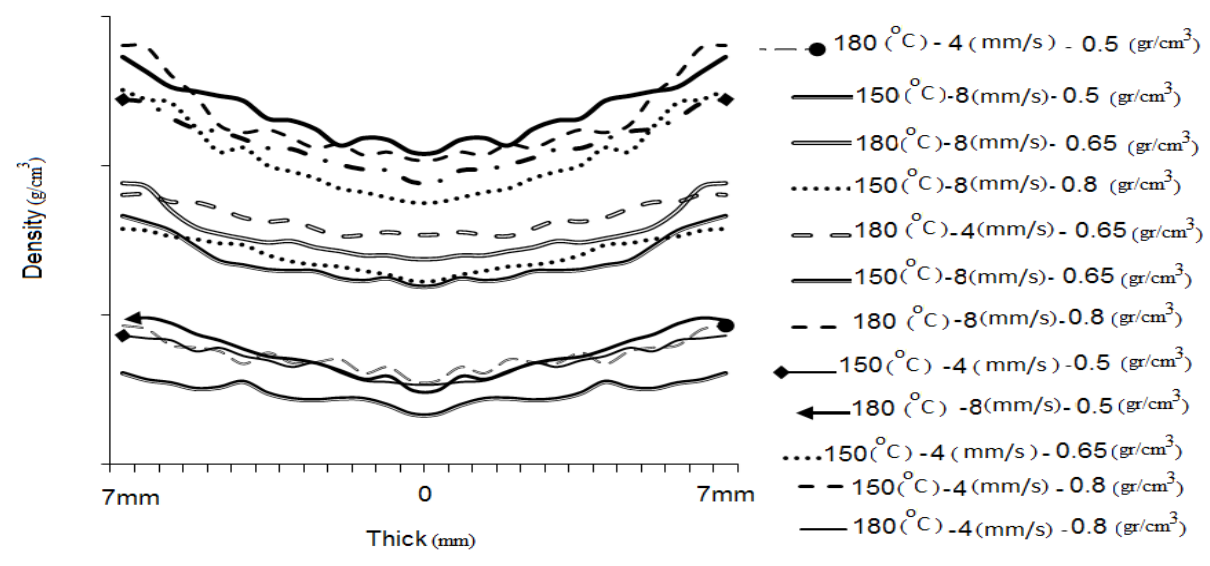

Figure 6. Thickness density profile of panels.

Decreasing the closing speed of the press opening, a more uniform density profile is created (Figure 6). As a result, the mechanical interlocking of particles improves; core layers are interwoven and more compact. So, the particles are more overlapped and the contact area between the particles coated by resin improves and subsequently, the internal bonding increases (Wu and Suchland 1997).

The bilateral effect of the density and the press temperature (Figure 7a) and that of the density and the press closing speed (Figure $7 \mathrm{~b}$ ) on the specimens' internal bonding are significantly different at the level of confidence $99 \%$. According to the direct effect of any porous material on the penetration rate of heat at same moisture conditions, for the boards with higher density and temperature, the penetration rate of the vapor from the hot press plates is more than that of the boards with lower density and temperature. Hence, it can be predicted that under the press, core layer of heavy boards are exposed more to heat and resin condensation is more complete, particles are softer and the overlapping coefficient finally increases and therefore, the internal bonding improves (Janisaad and Kamal 2012). The bilateral effect of the press temperature and the press closing speed on the internal bonding was not significant. The mutual effect of the density, pressing temperature and the press closing speed on the internal bonding was significant at the level of confidence $95 \%$, and specimens with the density of 0,8 ; the temperature $180^{\circ} \mathrm{C}$ and closing speed $4 \mathrm{~mm} / \mathrm{s}$ had the highest internal bonding strength (Figure $7 \mathrm{c}$ ). 

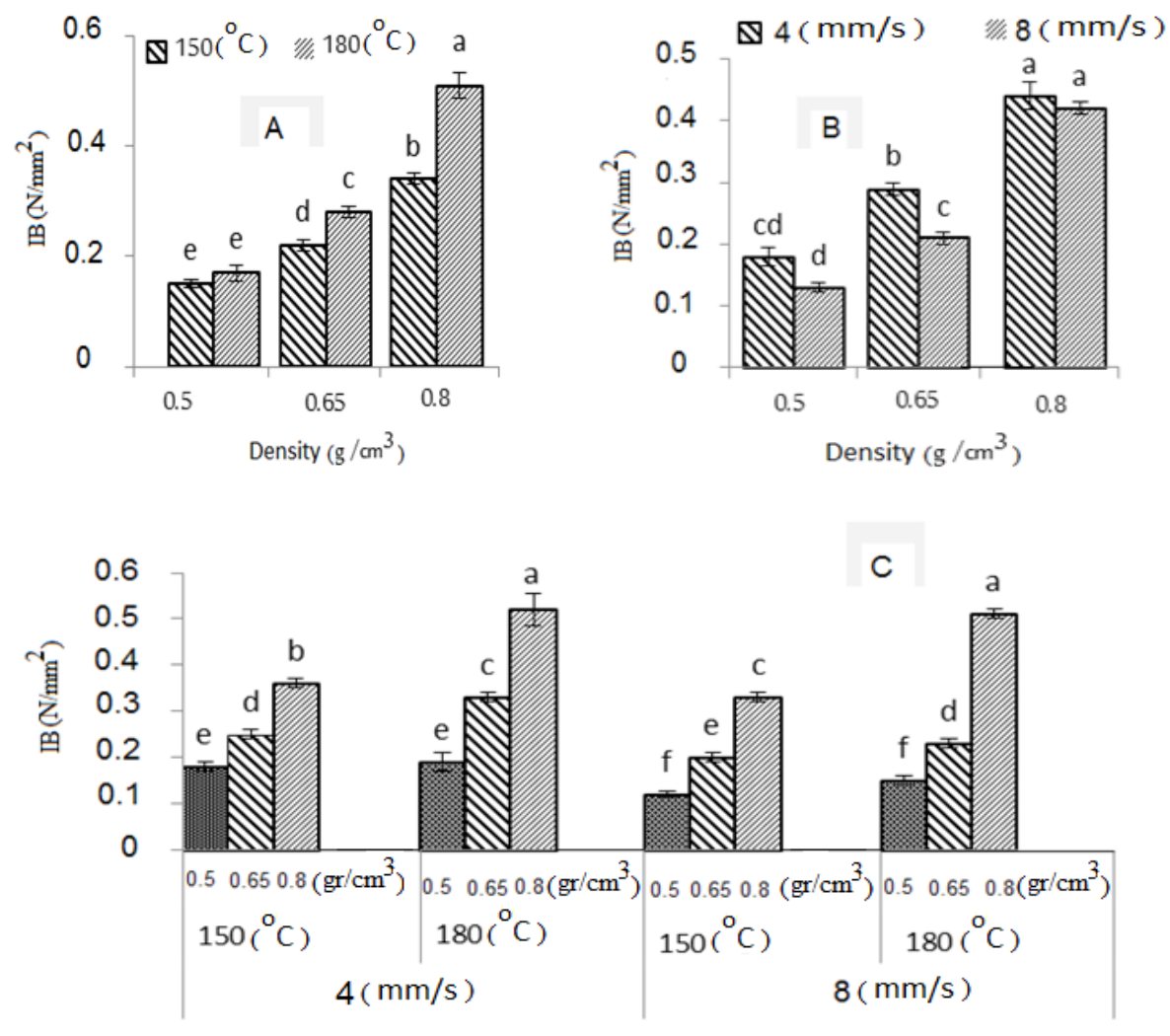

Figure 7. Bilateral effect of : panel density and press temperature (A); panel density and press closing speed (B) on IB and mutual effect of panel density, press tempreture and press closing speed on IB (C) Note: While the different letters on the columns represent statistical differences at $95 \%$ confidence level, values having the same letter are not significantly different (Duncan's Multiple Range Test).

The results showed that the independent effect of density and press temperature on the specimens' water absorption is significant at the level of confidence $99 \%$, so that by increasing the density and press temperature, the specimens' water absorption decreases. This can be due to the higher contact area between particles and decrease in the empty spaces between them (Zheng 2006). In addition, decrease in porosity that is the main factor of water absorption improves the resin's performance (Dziurka et al. 2015). When temperature increases, hemicellulose chains are destroyed, and when $\mathrm{OH}-$ groups are destroyed, fibers, and hence the boards, are less hydrophilic. Increasing the temperature of the press plates, the board's core temperature increases sooner and so, connections are stronger and water absorption decreases due to the reduction of the thickness swelling. Moreover, increase in temperature stabilizes the cells at stable compression position and subsequently, it reduces water absorption (Sernek and Famke 2007). However, the effect of the press closing speed on the specimens' water absorption is not significant. The bilateral effect of the density and press temperature (Figure 8a) and that of the density and the press closing speed (Figure 8b) on water absorption are significant at the level of confidence $99 \%$ in a way that the surface layers of panels that were processed under $180 \mathrm{C}$, press closing speed $8 \mathrm{~mm} / \mathrm{s}$, and density of $0,8 \mathrm{~g} / \mathrm{cm}^{3}$ had the highest density, accordingly showed less water absorption. Increment in slope gradient density between the peak and the core regions (Figure 6) leads to a proportional decrease in core density. Decreasing core region density causes a decreasing in internal bond strength due to less compact and looser structure of this region and this, accordingly; increases thickness swelling, and consequently increases the water absorption of panels, although higher density of the surface layers gives the lower WA, especially at the beginning stage of the WA 
test. The bilateral effect of the press temperature and press closing speed and mutual effect of density, press temperature and the press closing speed on water absorption are not significant.

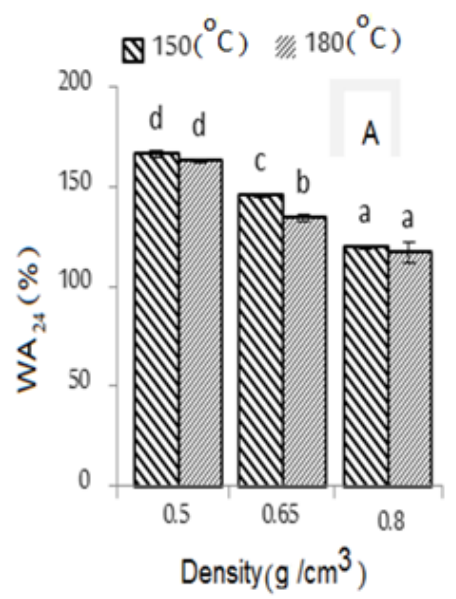

\$ $4(\mathrm{~mm} / \mathrm{s}) \quad 8(\mathrm{~mm} / \mathrm{s})$

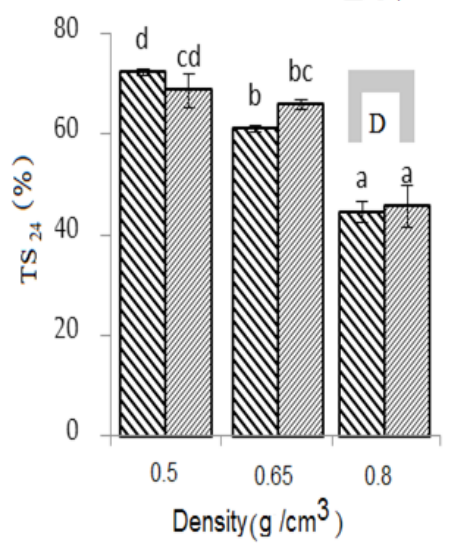

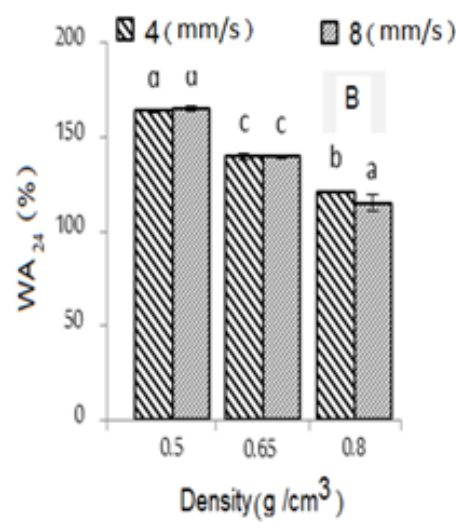

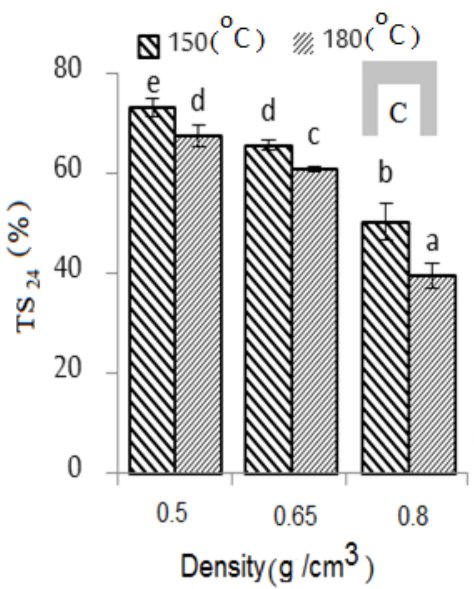

Figure 8. Bilateral effect of: panel density and press temperature on WA (A); panel density and press closing speed on WA (B); panel density and press tempreture on TS (C) and panel density and press closing speed on TS (D). Note: While the different letters on the columns represent statistical

differences at $95 \%$ confidence level, values having the same letter are not significantly different

(Duncan's Multiple Range Test).

The direct effect of the density and press temperature on the specimens' thickness swelling is significant at the level of confidence $99 \%$ (Table 1), so that the highest thickness swelling is for a specimen with the density of $0,5 \mathrm{~g} / \mathrm{cm}^{3}$ and the lowest thickness swelling is for a specimen with the density of $0,8 \mathrm{~g} / \mathrm{cm}^{3}$ (Figures 1 and 2). The most important factor of change in thickness swelling is porosity that corresponds to the board's density. When density increases, the porosity decreases. In addition, when particleboard's density increases more, stronger connections are produced due to the higher contact area between the particles and their higher overlap. This increases the internal bonding strength and finally, the particleboard's thickness swelling decreases. 
Also, through increasing the press temperature, the thickness swelling decreases, so that a specimen with the pressing temperature $180^{\circ} \mathrm{C}$ had the lowest thickness swelling. Particles exposed to high heat at the press stage undergo permanent irreversible (plastic) deformation. Hence, their thickness swelling decreases (Sernek and Famke 2007). Since the remaining stress of the board is minimum, the board's thickness return to its initial state due to water absorption will be minimum.

The bilateral effects of density and press temperature (Figure 8c) and that of density and press closing speed (Figure 8d) on the specimens' thickness swelling are significantly different at the level of confidence $99 \%$. The direct effect of the press closing speed on the specimens' thickness swelling is not significant. Also, the bilateral effect of temperature and press closing speed and mutual effect of density, press temperature and closing speed on the specimens' thickness swelling are not significant.

\section{CONCLUSIONS}

Through increasing the temperature from 150 to $180^{\circ} \mathrm{C}$, the specimens' MOR and their MOE increased. This may be due to the increase in softening, compacting, and also speed of reaching to the plastic point of particles. By increasing the closing speed of the press opening from 4 to $8 \mathrm{~mm} / \mathrm{s}$, the specimens' MOR and MOE increased due to more stiffening of surface layers of boards. The samples manufactured at the temperature $180^{\circ} \mathrm{C}$, with the press closing speed $8 \mathrm{~mm} / \mathrm{s}$ and the density of $0,8 \mathrm{~g} / \mathrm{cm}^{3}$ had the highest density at the surface layers.

Samples with lower press closing speed had the higher internal bonding. Specimens made at the temperature $180^{\circ} \mathrm{C}$ and with the press closing time $4 \mathrm{~mm} / \mathrm{s}$ had the highest IB. Decreasing the press closing speed, more time is provided for core layer and the particles are interwoven more; and the core layer's density increases, while the average density is constant and hence, the IB increases.

Increasing the density and press temperature, the specimens' water absorption decreased due to the higher contact area between particles and decrease in the empty spaces between them. However, the effect of the press closing speed on the specimens' water absorption was not significant. The highest thickness swelling was for a specimen with the density of $0,5 \mathrm{~g} / \mathrm{cm}^{3}$ and the lowest thickness swelling was for a specimen with the density of $0,8 \mathrm{~g} / \mathrm{cm}^{3}$. By increasing the press temperature, the thickness swelling decreased, so that a specimen with the pressing temperature $180^{\circ} \mathrm{C}$ had the lowest thickness swelling. 


\section{REFERENCES}

Candan, Z.; Akbulut, T. 2015. Physical and mechanical properties of nanoreiforced particleboard composites. Maderas. Ciencia y Tecnologia 17(2): 319-334.

Dziurka, D.; Mirski, R.; Dukarska, D.; Derkowski, A. 2015. Possibility of using the expanded polystyrene and rape straw to the manufacture of lightweight particleboard. Maderas. Ciencia $y$ Tecnologia 17(3): 647-656.

European Standardization Committee. EN. 1999. Wood based panels, determination of modulus of elasticity in bending and bending strength. EN 310. Brussell. Belgium.

European Standardization Committee. 1999. Particleboards and fiberboards. Determination of tensile strength. EN 319. Brussell. Belgium.

European Standardization Committee. 1999. Particleboards and fiber boards, determination of swelling in thickness after immersion. EN 317. Brussell, 1999.

European Standardization Committee. 1999. Wood Based Panels: Sampling, Cutting and Inspection. «Sampling and Cutting of Test Pieces and Expression of Test Results". EN 326. Brussels, Belgium.

Guler, C.; Bektas, I.; Kalaycioglu, H. 2006. The experimental particleboard manufacture from sunflower stalks (Helianthus annuus L.) and Calabrian pine (Pinus brutia Ten.). Forest Products Journal 56(4): 56-60.

Hiziroglu, S.; Jarusombuti, S; Fuengvivat, V. 2005. Surface Characteristics of Wood Composites Manufactured in Thailand. Building and Environment 39:1359-1364.

JaniSaad, M.; Kamal, I. 2012. Mechanical and Physical Properties of Low Density Kenaf Core Particleboards Bonded with Different Resins. Journal of Science and Technology 17- 32.

Kadja,K.; Banna, M.; Atcholi, K. E.; Sanda, K. 2011. Utilization of Bone Adhesive to Produce Particleboards from Stems of Cotton Plant at the Pressing Temperature of $140^{\circ} \mathrm{C}$. American Journal of Applied Sciences 8(4): 318-322.

Kalaycioglu, H.; Nemli, G. 2006. Producing composite particleboard from kenaf (Hibiscus cannabinus L.) stalks. Industrial Crops and Products 24: 177-180.

Kargarfard, A.; Nourbakhsh, A.; Golbabaei, F. 2006. Investigation on utilization of cotton stalk in particleboard production. Iranian Journal of Wood and Paper Science Research 21(2): 95-104.

Kehr, E; Schoelzel, S. 1967. Investigations of the Pressing Diagram II. Influence of Chip moisture, Mould closing time, and Mould pressure on the Compression Characteristics during hot Pressing of Particleboard. Holztechnologie 8(3):177 - 181. USDA Translation FPL-678.

Kord, B.; Roohani, M.; Kord, B. 2015. Characterization and utilization of reed stem as a lignocellulosic resource for particleboard production. Maderas. Ciencia y Tecnologia 17(3): 517-524.

Neusser, H.; Krames, U. 1969. Determination of some impactional wood chip indexes. Holzforschung and Holzvewerrung 21(4): 77-80.

Okubo, K.; Fujii, T.; Yamamoto, Y. 2004. Development of bamboo-based polymer composites and their mechanical properties. Composites Part A: Applied Science and Manufacturing 35: 377-383. 
Sernek, M.; Kamke, F.A. 2007. Application of dielectric analysis for monitoring the cure process of phenol formaldehyde adhesive. International Journal of Adhesion and Adhesives 27:562-567.

Shokouhi, M. 1997. Comparison evaluation of soda and craft process application in cotton stalk cooking. Thesis of M.Sc. agriculture and natural resources science of Gorgan . 145 page.

Tabarsa, T.; Chui, H. 2000. Wood behavior in transverse compression. Part1 :apparatus and preliminary results. Wood and Fiber Science 32(2):144-15.

Tousi, E.T.; Hashim, R.; Bauk, S.; Suhaimi Jaafar, M.; Abuarra, A.M.H.; Al-Jarrah, A.M.; Ababneh, B.; Tousi, A.T.; Aldroobi, K.S.A. 2015. Characterization of the rhizophora particleboard as a tissue-equivalent phantom material bonded with bio-based adhesive. Maderas. Ciencia y Tecnologia 17(2): 305- 318 .

Wang, S.; Winistorfer, P.M.; Young, T.M. 2004. Fundamentals of vertical density profile formation in wood composites. Part 3. MDF density formation during Hot-pressing. Wood and Fiber Science 36(1): 17-25.

Warmbier, K.; Wilczynski, A.; Danecki, L. 2013. Properties of one-layer experimental particleboards from willow (Salix viminalis) and industrial wood particles. European Journal of Wood and Wood Products 71: 25-28.

Wu, O.; Suchland, O. 1997. Effect of moisture on the flexural properties of commercial oriented strand panels. Wood and Fiber Science 29: 47-57.

Zheng, Y.; Pan, Z.; Zhang R.; JenkinsB.M.; Blunk, S. 2006. Properties of medium-density particleboard from saline Athel wood. Industrial Crops and Products 23: 318-326. 